\title{
FATORES QUE LEVAM À BAIXA COBERTURA VACINAL DE CRIANÇAS E O PAPEL DA ENFERMAGEM - REVISÃO LITERÁRIA
}

\author{
FACTORS THAT LEAD TO LOW VACCINE COVERAGE OF CHILDREN AND \\ THE ROLE OF NURSING - LITERARY REVIEW
}

\section{Jakeline Nascimento Moraisa, Maria Salete Vaceli Quintilioa*}

Faculdade de Ciências e Educação Sena Aires - FACESA E-mail: saletevaceli@senaaires.com.br

\section{RESUMO}

A imunização pode ser definida como uma ação integrada e rotineira dos serviços de saúde com o intuito de erradicar, eliminar e/ou controlar as doenças imunopreveníveis. Este estudo tem o objetivo de avaliar os fatores que interferem na cobertura vacinal de crianças no Brasil e o papel da enfermagem nesse processo. Nesta Revisão de Literatura, incluíram-se artigos científicos publicados nos últimos dez anos, disponíveis nas principais bases de dados da área da saúde, usando como critério de inclusão os descritores: Enfermagem, saúde da criança, vacinação, cobertura vacinal. Vários fatores foram identificados como influenciadores na cobertura vacinal em crianças, entre eles: as questões culturais preestabelecidas pelos pais, falta de imubiológicos ou má conservação dos mesmos, dificuldades de acesso às unidades de saúde, falta de informações sobre a importância da vacinação, ação dos movimentos antivacina, fake news (notícias falsas) e, neste último ano, a pandemia atual do novo Coronavírus. O papel da enfermagem nesse contexto deve possibilitar a adoção de medidas de educação em saúde (campanhas, palestras, divulgação), além de interagir ativamente com a população-alvo. Em suma, medidas precisam ser tomadas para um atendimento integral relacionado à imunização, principalmente em crianças e, para isso, os profissionais de saúde devem trabalhar de maneira articulada e sistemática a fim de intervir na realidade atual buscando sua melhoria.

Palavras-chave: Enfermagem; saúde da criança; vacinação; cobertura vacinal.

\section{ABSTRACT}

Immunization can be defined as an integrated and routine action by health services in order to eradicate, eliminate and / or control immunopreventable diseases. This study aims to assess the factors that interfere in the vaccination coverage of children in Brazil and the role of nursing in this process. This is a Systematic Literature Review carried out through the selection of scientific articles made up of observational studies published in the last ten years. For that, we searched for works available in the main databases in the health area, using as descriptors the inclusion criteria: Nursing, child health, vaccination, vaccination coverage. Several factors have been identified as influencing the vaccination coverage in children, among them: cultural issues pre-established by parents, lack of antibiotics or poor conservation, difficulties in accessing health facilities, lack of information on the importance of vaccination, action by anti-vaccine movements, fake news and, this past year, the current pandemic of the new Coronavirus. The role of nursing in this context should enable the adoption of health education measures (campaigns, lectures, dissemination), in addition to actively interacting with the target population. In short, measures need to be taken for comprehensive care related to immunization, especially in children and, for this, health professionals must work in an articulated and systematic manner in order to intervene in the current reality seeking its improvement.

Keyword: Nursing, child health; vaccination; vaccination coverage. 


\section{INTRODUÇÃO}

As vacinas são constituídas por substâncias com vírus ou bactérias inativadas, ou micro-organismos inteiros vivos e/ou atenuados, que, ao serem introduzidos no organismo de uma pessoa, estimulam o sistema imune a desenvolver anticorpos, produzindo, assim, uma defesa contra os agentes que provocariam a doença. Estes anticorpos ativam células de memória do sistema imunológico, de forma a evitar que o indivíduo desenvolva novamente a doença ao ser reexposto, caracterizando assim a imunidade (SOUSA et al, 2012).

A ação integrada e rotineira dos serviços de saúde tem o intuito de erradicar, eliminar e/ou controlar as doenças imunopreveníveis no território brasileiro, pois a vacinação fornece proteção específica contra algumas doenças graves, causadoras de danos irreversíveis ou letais. Além disso, proporciona uma melhora no nível de saúde da comunidade e isso se reflete diretamente nos indicadores epidemiológicos especialmente na taxa de mortalidade infantil. É também uma das medidas mais eficazes e que tem melhor custo-benefício (CARNEIRO et al, 2013; BARBIERI et al, 2013).

As primeiras vacinações no Brasil foram realizadas em 1804 e desde então, foram utilizadas diversas estratégias de divulgação para a sua realização como campanhas publicitárias, varreduras, rotina e bloqueios (JESUS et al, 2016).

Neste contexto, foi criado em 1973 o Programa Nacional de Imunização (PNI), cuja evolução levou à descentralização de suas ações em 1988, a qual conferiu aos municípios a responsabilidade pelas atividades de imunização, cujas estratégias consistem em vacinação de rotina, das campanhas e ações específicas de sensibilização e divulgação (ELISIÁRIO et al, 2017).

Estima-se que mais de 30 (trinta) doses de vacina são administradas globalmente a cada segundo e nenhuma outra intervenção de saúde atinge um público tão grande, ou é capaz de prevenir uma quantidade tão variada de problemas de saúde pública (FERREIRA et al, 2017).

Para que uma criança seja considerada imunizada, ela deve estar em dia com o programa vacinal preconizado para cada idade, uma vez que o atraso na vacinação pode ser tão prejudicial quanto sua ausência. Além do fato de a criança não imunizada ter uma chance maior de desenvolver doenças, isso incorre em maior risco comunitário de epidemias, principalmente quando se trata de vacina em dose única, cujo esquecimento leva à ausência total de proteção. (FERNANDES et al, 2015)

Um estudo financiado pelo Programa de
Pesquisa Intramural da Fundação Oswaldo Cruz (Fiocruz) e publicado em junho de 2020, no International Journal of Infectious Diseases, apontou expressiva queda na imunização brasileira, especialmente em bebês e crianças (CNN Brasil, 2020).

Oliveira e colaboradores classificam em quatro dimensões os fatores que podem interferir na cobertura vacinal: sistema de imunização (política), estrutura de distribuição de vacinas; atitudes e conhecimento dos pais quanto à vacinação; comunicação e informação; e características familiares (OLIVEIRA et al, 2014).

$\mathrm{O}$ conhecimento dos gestores e profissionais envolvidos nas campanhas e na vacinação em si, é de extrema importância para que os fatores descritos acima possam ser minimizados ou até eliminados, garantindo o sucesso e alcance da cobertura vacinal (ALVES et al, 2020).

Como apontado por Silva e Cunha (2018), a capacitação dos profissionais que trabalham na sala de vacina, em relação ao acolhimento, condições de uso e à temperatura adequada das vacinas, é tarefa da equipe de enfermagem, que, além disso, administra as vacinas segundo os protocolos e as técnicas definidas pelo Programa Nacional de Imunizações.

A equipe de enfermagem ainda é responsável pelas orientações aos usuários quanto à possíveis reações e contraindicações da vacina. Este conhecimento possibilita a saúde, prevenção e qualidade de vida da população conforme o PNI e as diretrizes do SUS (Sistema Único de Saúde). Neste contexto, a equipe de Enfermagem tem relevância fundamental no que se refere à qualidade do serviço prestado ao usuário, pois está envolvida em todas as etapas do processo, desde a conservação das vacinas, até a imunização da população (SILVA; CUNHA, 2018).

Este estudo teve como objetivo realizar uma Revisão Literária acerca da percepção da equipe de enfermagem sobre a cobertura vacinal em crianças no território brasileiro e seu déficit atual.

\section{MÉTODOS}

A percepção dos enfermeiros acerca da cobertura vacinal em crianças é tratada em vários artigos científicos. A partir deste enfoque, este estudo traz uma Revisão de Literatura, um método de pesquisa que se fundamenta em obras já publicadas com evidências científicas comprovadas. O objetivo é reunir e condensar resultados de pesquisas sobre um tema ou problema de forma organizada e sistemática, gerando contribuição e 
aperfeiçoamento sobre o tema investigado (STÁBILI et al, 2013).

A busca foi executada em bases de dados científicas gratuitas tais como SciELO, PubMed, BVS (Biblioteca Virtual em Saúde) e LILACs, englobando artigos publicados nos últimos dez anos (2010 a 2020). Para seleção de artigos foram usados os seguintes descritores cadastrados no DeCs como critério de inclusão: Enfermagem, saúde da criança, vacinação, cobertura vacinal.

Foram selecionados artigos que abordam o cenário nacional das campanhas vacinais infantis e o impacto das atividades dos profissionais da enfermagem neste panorama.

\section{RESULTADOS E DISCUSSÃO}

\section{Vacinação infantil: Histórico}

A primeira vacina foi descoberta por Edward Jenner em 1796, após 20 anos de estudos e experimentos com a varíola bovina, dando origem aos termos vaccine e vaccination (derivados do termo latino vacca.) (APS et al, 2018).

Historicamente, a vacinação ganhou credibilidade com o êxito da vacina contra a varíola. Trata-se da forma mais fácil de proteção contra doenças infectocontagiosas, pois, ao serem administradas a indivíduos imunocompetentes, induzem um estado específico de imunidade contra os efeitos nocivos do agente relacionado (PEIXOTO et al, 2017).

A imunização pode ser entendida como o ato de tornar o corpo humano resistente a determinado patógeno, e pode ser classificada como imunidade ativa e passiva. A ativa é estimulada pelo organismo através do sistema imunológico, o que resulta na produção de anticorpos específicos. Já a imunização passiva realiza uma proteção temporária: o indivíduo recebe anticorpos produzidos de forma exógena, que pode ser artificial, através de soros hierólogos/homólogos (vacinas) ou repassada de forma natural, através do colostro ou via transplacentária ao bebê (PEREIRA; IVO, 2016).

O objetivo da imunização infantil é prevenir e proteger as crianças das doenças prevalentes na infância e/ou reduzir, ao máximo, o seu aparecimento. A vacinação infantil tem alcançado êxito em vários países, devido ao grande sucesso na adesão à vacinação, assim como importantes progressos na fiscalização $\mathrm{e}$ aniquilação de doenças (PEREIRA; IVO, 2016).

A vacinação permite, assim, que doenças imunopreveníveis possam ser combatidas quando contraídas individualmente, e ainda, possibilita que se evite sua transmissão para a coletividade (CAVALCANTI; NASCIMENTO, 2015).

A vacinação constitui-se como uma das intervenções em saúde mais custo-efetivas e seguras, apresentando-se como componente obrigatório dos programas de saúde. Sua disposição é fundamental para as crianças, preconizando-se o acompanhamento da vacinação durante o período que se estende até os 5 (cinco) primeiros anos de vida, para evitar as ocorrências de determinadas doenças típicas da infância, como a difteria, tétano, coqueluche, meningite, poliomielite, hepatite $\mathrm{B}$, tuberculose, diarreia por rotavírus, febre amarela, sarampo, caxumba e rubéola (CAVALCANTI; NASCIMENTO, 2015).

É inegável o impacto da vacinação na saúde pública. Com exceção da distribuição de água potável, nenhuma outra intervenção, nem mesmo o uso de antibióticos, teve ao longo dos anos um efeito tão contundente na redução da mortalidade e no crescimento populacional a nível mundial (COSTA, 2016).

As vacinas são rigorosamente testadas e monitoradas pelos seus fabricantes e pelos sistemas de saúde dos países onde são aplicadas. O licenciamento e a comercialização de vacinas ocorrem após aprovação de órgãos reguladores específicos e estudos clínicos cuidadosos, caros e demorados, com voluntários credenciados (APS et al,2018).

O público infantil tem prioridade nas políticas de atenção do Ministério da Saúde e é nesse sentido que a vacinação vem alcançando êxito em diversos países, por meio de altas coberturas vacinais e consideráveis avanços no controle e erradicação de doenças, já que as vacinas atuam na proteção à saúde e na prevenção de doenças a partir dos primeiros dias de vida (PEIXOTO et al, 2017).

O Programa Nacional de Imunização (PNI), criado em 1973, tem a finalidade de tornar os imunobiológicos acessíveis a toda a população, contribuindo para o controle, eliminação e/ou erradicação de doenças imunopreveníveis, utilizando para isso estratégias diferenciadas de vacinação. Tornouse um programa tido como referência mundial pela adoção de estratégias diferenciadas para garantir alta cobertura, como a vacinação de rotina, campanhas anuais de vacinação, estabelecimento de metas, ampliação da população-alvo, e por sua política de parcerias e incentivo à ampliação e modernização tecnológica da produção nacional de imunobiológicos (PEREIRA et al, 2013; CASTRO; CABRERA, 2017).

Atualmente, o PNI é um programa com múltiplos avanços, como por exemplo, a inclusão de 
novas vacinas e novos grupos alvos, assim como a sua modernização no campo da informática e da informação. Apesar de alcançar metas cada vez mais elevadas em várias regiões brasileiras, estudos mostram que alguns agravos ainda se fazem reemergentes, justificando algumas intervenções no grupo de menores de cinco anos (CASTRO; CABRERA, 2017).

O Sistema de Informação disponível deste programa fornece relatórios anuais de cobertura vacinal por tipos de vacinas, sendo que os cálculos são feitos com base no número de doses aplicadas de uma vacina específica e a população estimada de crianças na faixa etária recomendada para recebê-la (ROCHA, 2020).

Para que a meta do PNI de fornecer vacinas com qualidade a todas as crianças seja alcançada, obtendo coberturas vacinais de $95 \%$ e de forma homogênea, alguns desafios ainda precisam ser superados. Entre eles, o de manter as altas coberturas para as vacinas já incorporadas anteriormente, alcançar boas coberturas para as novas vacinas e conquistar alta homogeneidade de coberturas para todas (ROCHA, 2020).

\section{A cobertura vacinal no Brasil: cenário atual}

É importante salientar que a cobertura vacinal informa o percentual de crianças imunizadas e estima o nível de proteção da população infantil contra determinada doença. Apesar dos altos níveis de cobertura vacinal no Brasil desde a década de 1990, a partir de 2016, as coberturas declinaram e como consequência, por exemplo, em Roraima e no Amazonas, ocorreram epidemias de sarampo (OLIVEIRA et al, 2020).

A obrigatoriedade de vacinação de menores é afirmada pelo disposto no Estatuto da Criança e do Adolescente (ECA) - Lei no 8.069/90 5 - que regulamentou o artigo 227 da Constituição Federal de 1988, visando estabelecer os direitos e a proteção integral a essa população. O ECA, no parágrafo único do Art. 14, estabelece que "é obrigatória a vacinação das crianças nos casos recomendados pelas autoridades sanitárias" (IGREJA et al, 2020).

A imunização é um processo ativo e que depende, principalmente, da iniciativa do responsável pela criança (FERNANDES et al, 2015). A hesitação desses responsáveis é um comportamento que afeta negativamente a cobertura vacinal e sua causa tem influência de diversos fatores, como a falta de acesso à informação em saúde, baixa percepção de risco de contrair doenças infecciosas por parte da população, desconfiança sobre a eficácia e segurança das vacinas e também a falta de vínculo da população com as ações de vacinação. Como resultado direto desse comportamento a população torna-se vulnerável devido à queda da cobertura vacinal (OLIVEIRA et al, 2020).

Apesar das vacinas serem fornecidas e sua aplicação incentivada pelo Ministério da Saúde, ainda existem crianças não imunizadas corretamente. Isto se deve a vários fatores, entre eles: superstições, mitos, informações preconceituosas e errôneas, e, o mais importante deles, o nível cultural e socioeconômico dos cuidadores e responsáveis, em especial as mães. Então, as mães como agentes indispensáveis no processo de cobertura vacinal de suas crianças, devem ser sensibilizadas e esclarecidas com relação ao entendimento dessa prática de saúde. A equipe de saúde deve se comprometer a fornecer o acesso às informações corretas sobre as vacinas, obtendo a compreensão de que a vacinação constitui uma das medidas mais favoráveis e importantes para manter o bem-estar da criança (SOARES et al, 2020).

As decisões sobre a imunização na infância não são simples para as mães. Muitas vezes elas são resistentes e ficam ansiosas a respeito da segurança das vacinas. Em contrapartida, muitas delas têm uma avaliação positiva dos benefícios que a imunização proporciona ao filho, porém ficam preocupadas em submeter suas crianças a procedimentos dolorosos ou a eventuais efeitos colaterais (SOARES et al, 2020).

Em um estudo realizado no Rio de Janeiro com crianças até dois anos, verificou-se um número bastante expressivo de cadernetas de vacinação atrasadas $(28,1 \%)$, considerando as inúmeras estratégias existentes em relação à vacinação de crianças vigentes no país. Esse número revela uma dissonância em relação à meta estabelecida pelo Ministério da Saúde: cobertura vacinal para $95 \%$ das crianças menores de um ano, exceto em relação à BCG, cuja cobertura preconizada é de $90 \%$. Segundo o autor do estudo, alguns fatores que implicam diretamente na atualização da caderneta são: A localização de residência, condição socioeconômica, infraestrutura do serviço de saúde, abastecimento adequado de imunobiológicos, tempo de espera para receber a vacina, entre outros (FILGUEIRAS et al, 2018).

Em outro estudo recente, feito por Barbiere et al. (2017) e realizado com casais de classe média de São Paulo, as justificativas relatadas para a decisão pela não vacinação foram: o argumento de que a doença está erradicada ou ela é leve, medo dos eventos adversos, crítica à composição das vacinas, à sua eficácia, ao calendário de vacinação preconizado no Brasil, ao interesse financeiro e lucro das indústrias farmacêuticas 
e escolha de outras formas de proteção à saúde (como o estilo de vida mais natural).

Um estudo feito por Fernandes et al. (2015) constatou que uma em cada quatro crianças observada teve atraso vacinal quando computadas as doses atualizadas com atraso e as não administradas, o que pode ser considerado preocupante se comparado às metas do PNI. Os motivos expressados pelos pais para o atraso vacinal e/ou para a não-vacinação, foram, em sua maioria, a falta de vacinas e a negligência. A falta de vacinas possivelmente vem de perdas decorrentes do vencimento do prazo de validade, quebra de frascos e problemas como o manuseio inadequado, ou ainda, um equipamento com defeito ou a falta de energia elétrica que interrompem o processo de refrigeração, comprometendo a potência dos imunobiológicos. De acordo com os autores, quanto mais doses a vacina tiver no programa, maiores são as chances de atrasos vacinais. Presume-se que o responsável pela criança julgue essas doses subsequentes menos importantes e, por isso, dispensáveis. Vacinas em dose única dificilmente deixam de ser administradas.

Um estudo de Peixoto et al. (2017) que analisou os cartões vacinais de 536 crianças de 0-4 anos, concluiu que a vacina que apresentou maior número de crianças faltosas foi a da febre amarela, com um total de 361 crianças sem vacinar, seguida da vacina contra a hepatite B, com um total de 332 crianças sem imunização. A terceira posição é ocupada pela vacina inativada contra a poliomielite (VIP), somando 302 crianças sem vacinar. Para a vacina contra a meningite $\mathrm{C}$, pneumocócica e poliomielite (VOP) 107, 102 e 92 crianças, respectivamente, não foram vacinadas. Com índices mais baixos, estão as vacinas tríplice viral, rotavírus e pentavalente, totalizando 47, 42, 33 atrasos, respectivamente. A vacina que obteve menor número de crianças sem imunização foi a vacina BCG, com um total de quatro crianças.

No que diz respeito às informações e notícias falsas ou maliciosas (fake News) veiculadas principalmente nas mídias digitais, e seus impactos na saúde, podemos dizer que este é um tema extremamente preocupante. Têm-se relatos de que doenças já controladas e erradicadas ressurgiram em alguns países, como, por exemplo, o sarampo. Boa parte da negativa da população em aceitar a imunização dessas doenças pelas vacinas é proveniente do desconhecimento e da falta de informações adequadas e eficazes, ou ainda, a propagação das fake news. Muitas pessoas não se utilizam das vacinas por questões filosóficas ou religiosas, mas uma boa parte da população realmente não tem conhecimento a respeito do potencial danos à saúde advindo da recusa da imunização (SANCHES; CAVALCANTI, 2018).

Vale a pena mencionar também os movimentos anti-vacinas. Segundo Camargo Junior (2020), os principais tipos de argumentos defendidos por esses ativistas podem ser agrupados em: ingredientes perigosos; lesão vacinal; argumentos de autoridade baseados em material duvidoso produzido por "experts" questionáveis atestando que as doenças teriam diminuído por outras razões que não as vacinas e/ou não teriam diminuído de forma nenhuma, haveria demasiadas vacinas, e seriam dadas num curto período de tempo, a imunidade "natural" seria melhor, os pais (especialmente as mães) teriam maior conhecimento que os órgãos públicos, etc.

Em meio à pandemia do novo coronavírus, as equipes de saúde perceberam atrasos na busca pela vacinação inclusive neste ano, o que indica uma real possibilidade de queda histórica nos índices. Para Marli Rodrigues, presidente do SindSaúde, diversas questões podem contribuir para a não-vacinação. "A falsa sensação de que algumas doenças não existem mais, a dificuldade de os responsáveis levarem suas crianças aos locais de vacinação e problemas na distribuição na rede de saúde" (SINDSAÚDE, 2020).

Dados preliminares do Programa Nacional de Imunização (PNI) e do Ministério da Saúde apontam que cerca de metade das crianças brasileiras não recebeu todas as vacinas previstas no Calendário Nacional de Imunização em 2020. Segundo os índices do PNI, a cobertura vacinal está em 51,6\% para as imunizações infantis. O ideal é que ela fique entre $90 \%$ e $95 \%$ para garantir proteção contra doenças como sarampo (que tem índice ideal de cobertura de $95 \%$ ), coqueluche, meningite e poliomielite. Neste ano, entretanto, a cobertura vacinal da primeira dose da tríplice viral (que protege contra sarampo, caxumba e rubéola) está abaixo de $60 \%$. A da segunda dose está abaixo de 50\%. Nenhuma das vacinas previstas no calendário infantil teve índices acima de 60\% (GLOBO, 2020).

Para Isabella Ballalai, pediatra e vice-presidente da Sociedade Brasileira de Imunizações (SBIm), o motivo da baixa cobertura é a pandemia de Covid-19, que levou as pessoas a ficarem em casa e não saírem para vacinar os filhos. Os motivos que levam os pais ou responsáveis a atrasarem o calendário de vacinação, segundo ela, são o que se conhece por "três Cs": a confiança, a complacência e a conveniência. Quando não existe confiança no profissional de saúde, será mais difícil os pais vacinarem a criança. A complacência 
acontece quando o risco não é percebido. Talvez, por não terem visto nenhum caso da doença recentemente, os pais demorem a vacinar seus filhos. A conveniência ocorre quando procuram o posto de saúde e a vacina não está disponível. Então não voltam mais. Túlio Batista Franco, que é professor do Instituto de Saúde Coletiva da Universidade Federal Fluminense (UFF), em Niterói (RJ), aponta a descoordenação existente no SUS e a dificuldade de acesso dos pais aos serviços de saúde, por trabalharem em horário comercial, como alguns fatores que levam à baixa cobertura vacinal (GLOBO, 2020).

Os dados do PNI mostram que o Distrito Federal é a unidade da federação (UF) com maior índice de cobertura vacinal infantil: fica próxima de $70 \%$. Em seguida vêm o Tocantins, com 64\%, Rondônia, com $61 \%$, e Minas Gerais e Espírito Santo, com 60\%. Os piores desempenhos foram nos estados do Amapá, com $25 \%$, o Maranhão, com 35,5\%, e o Rio de Janeiro, com $36 \%$ de cobertura. O Pará também teve cobertura abaixo de $40 \%$. Goiás ficou com 55,14\% de cobertura (GLOBO, 2020).

\section{Papel dos profissionais de saúde na vacinação infantil}

A equipe de saúde são os profissionais que tem o maior contato com as mães durante a vacinação, então é natural que sejam os responsáveis em transmitir as informações referentes a prevenção de doenças e imunização, contribuindo para que as mães sejam sensibilizadas acerca do valor da vacinação. Realizar palestras em comunidades, escolas, faculdades e nas empresas, podem também colaborar para a compreensão da relevância da vacina (SOARES et al, 2020).

Um estudo realizado no começo de 2020 por Igreja e colaboradores, acerca do conhecimento das mães a respeito de vacinação, destacou que, mesmo quando as mães possuíam um nível de escolaridade baixo, elas estavam bem orientadas quanto à importância de realizar a vacinação para prevenir diversas doenças. No entanto, elas ainda possuem dificuldades acerca do reconhecimento do nome dos imunobiológicos e sua relação com as doenças infecciosas que podem ser prevenidas através da vacinação. Outra carência de informação diz respeito à composição básica vacinal, o que pode levar a muita apreensão, principalmente com a terminologia, por exemplo, quando se refere que a vacina é constituída de "vírus vivo atenuado" como a BCG ou tríplice viral. $\mathrm{O}$ estudo relatou também que muitas mães não recebem a orientação condizente durante a vacinação, levando-se à conclusão de que os profissionais devem investir mais tempo e recursos com orientações e ações em saúde que colaborem para a aquisição de conhecimento adequado pelas mães sobre este assunto (IGREJA et al, 2020).

O planejamento de ações pela equipe de saúde é uma meta que pode solucionar grande parte das dificuldades enfrentadas pela população para a tomada de decisão para vacinar seus filhos, além de orientá-la quanto à importância da vacinação, sua segurança, eficácia e possíveis efeitos adversos, a fim de aumentar a adesão ao método, contribuindo, assim, para a melhoria da qualidade de saúde de todos (SOUSA et al, 2012).

Torna-se necessário abordar os motivos para as atuais baixas de cobertura vacinal e para a não adesão da vacinação por parte dos pais, motivos estes que muitas vezes estão relacionados ao desconhecimento em relação à importância das campanhas vacinais, mesmo nos dias atuais onde se veiculam diversas estratégias de divulgação. $O$ fato é que ainda têm uma parcela da população que não é alvejada com as informações necessárias (SOUSA et al, 2012; NASCIMENTO et al, 2020).

Os profissionais da saúde são indispensáveis nas campanhas de vacinação e sua divulgação, já que eles podem incentivar a participação ativa das mães no processo de imunização dos seus filhos. E ainda, cabe a eles ficarem atentos e identificar as maiores dificuldades que as mães sentem ao vacinar as suas crianças e transmitam as informações necessárias para tirar qualquer dúvida das mães que se dirigem a esses locais (SOARES et al, 2020).

$\mathrm{O}$ entendimento populacional quanto aos imunobiológicos, as doenças que estão sendo prevenidas e seus benefícios, contribuem para menor taxa de abandono da vacinação e maior promoção da saúde pública. É válido relembrar que a capacitação profissional adequada, além de ensinar as técnicas de aplicação segura das vacinas e o conhecimento das condutas em situações de efeitos adversos, é de suma importância (SANTOS et al, 2020).

A educação para a saúde tem um papel fundamental na enfermagem. A promoção, manutenção e restabelecimento da saúde exigem que os clientes recebam informação compreensível, permitindo-lhes desta forma tomar decisões, no âmbito da saúde, de forma fundamentada e muito frequentemente favoráveis à adesão à vacinação (COSTA, 2016).

Apesar da adoção de um calendário nacional de vacinação e de muitas vacinas serem oferecidas gratuitamente à população, sua aplicação depende do arbítrio dos pais em levarem as crianças para serem vacinadas. Por outro lado, é fundamental o compromisso 
da equipe de saúde na promoção de educação em saúde e na reorganização das práticas de saúde nas salas de vacinação como forma de atrair o público alvo, assim como a corresponsabilização pela proteção do cliente. Estes são passos para uma ação mais abrangente destinada à busca da solução dos problemas de saúde e, em especial, a melhoria da cobertura vacinal (PEIXOTO et al, 2017).

Quando atuante na sala de vacinação, o profissional de enfermagem, de forma eficaz, pode ajudar e orientar os pais a serem mais participativos e terem um comportamento saudável, o que contribui para a promoção da saúde e prevenção de agravos, bem como também de epidemias e surtos, o que gera impactos positivos na redução da mortalidade infantil. Dessa forma, o papel dos profissionais de saúde engloba a busca ativa dos faltosos à vacinação, a revisão dos cartões de vacinação e a ampliação das visitas domiciliares (PEIXOTO et al, 2017).

Assim, observa-se que esses profissionais devem integrar a prática de procedimentos técnicos de enfermagem com a educação em saúde durante a execução do processo de imunização. Há reflexões sobre a importância da incorporação de novas tecnologias educativas no processo de educação em saúde na atualidade, as quais contribuem para democratização da comunicação, da educação e do conhecimento a partir da realidade cultural dos indivíduos (ARAGÃO et al, 2019).

Seguindo esta vertente, o Ministério da Saúde indica três ações que podem ser executadas para evitar a falta de vacinação, que são: sensibilizar os profissionais para que se comprometam com a vacinação das pessoas que buscam os serviços de saúde; revisar sistematicamente o cartão da criança; destacar o valor do uso do cartão de vacina; organizar e garantir o funcionamento efetivo do serviço de vacinação (com pessoal capacitado, material disponível e o quantitativo de vacinas) e propiciar o acompanhamento sistemático do calendário de vacinação (FILGUEIRAS et al, 2018).

Diante do exposto, percebe-se que a enfermagem é essencial para esse processo vital que é a imunização infantil e seu papel engloba principalmente a educação em saúde, orientando e informando aos pais, tirando suas dúvidas e, assim, sanando seus medos, a fim de que os mesmos possam se sentir seguros e entender a importância de vacinar seus filhos. A enfermagem deve também atuar ativamente na busca dos faltosos. Tudo isso pode contribuir para mudar os índices atuais de cobertura vacinal de forma significativa, garantindo a prevenção e erradicação de doenças imunopreveníveis.

\section{CONCLUSÃO}

O Brasil, sendo referência em vacina, passa por um momento crítico em relação à cobertura vacinal, evidenciando um alto risco à população. Uma vez que temos um dos melhores e mais amplos programas de imunização, a queda na eficiência apontada pelos dados se cobre de importância significativa.

Este estudo possibilitou a identificação de vários fatores que interferem na cobertura vacinal de crianças. Dentre eles, destacam-se as questões culturais e ideológicas, tais como crenças de que a vacina faz mal e medo de seus efeitos adversos e/ou colaterais; falta de imubiológicos ou má conservação dos mesmos; dificuldades de acesso às unidades de saúde pelos pais que trabalham em horário comercial; a falta de acesso à informação em saúde e ações de vacinação; baixa percepção de risco de contrair doenças infecciosas por parte da população; desconfiança sobre a eficácia e segurança das vacinas, além do argumento de que a doença está erradicada ou ela é leve; escolha de outras formas de proteção à saúde mais naturalistas.

A literatura ressalta também a ação dos movimentos anti-vacinas, as fake news e a pandemia atual do Novo Coronavírus como fatores para atraso na busca pela vacinação.

A equipe de enfermagem atuante nas salas de vacina encontra-se em posição privilegiada para auxiliar na sensibilização de pais e responsáveis acerca da importância da imunização infantil. Por terem um maior contato com as mães durante a vacinação, a equipe pode transmitir informações referentes a prevenção de doenças e imunização, amainar seus medos, dúvidas e barreiras, contribuindo para que elas percebam o valor da vacinação.

Realizar palestras em comunidades, escolas, faculdades e nas empresas, também são ações que podem colaborar para o entendimento da importância da vacina. O papel dos profissionais de saúde engloba também a busca ativa dos faltosos à vacinação, a revisão dos cartões de vacina e a intensificação das visitas domiciliares. Dessa forma, observa-se que esses profissionais devem unir sua prática com a educação em saúde para mudar o atual cenário de baixa adesão à imunização.

Com essas informações, espera-se que essa revisão literária possa contribuir para uma visão mais abrangente ao cenário atual anormalmente baixo da cobertura vacinal no Brasil. Além disso, espera-se a compreensão dos profissionais da saúde no sentido de trabalhar de maneira articulada e sistemática, para que os objetivos sejam alcançados de maneira concreta e os 
resultados sejam satisfatórios no presente e futuro.

\section{REFERENCES}

ALVES, L.C.; SOUZA, T.A.; LEITE, N.S.K.; MEDEIROS R.C.; BARRETO, C.C.M.; NOBRE, J.O.C. Avaliação da cobertura da vacina DTP no período de 2011 a 2016 no município de Itaporanga - PB. BAHE - Brazilian Archives of Health and Environment, v. 1, n. 1, p. 43-51, 2020

APS, L. de M. M. et al. Eventos adversos de vacinas e as consequências da não vacinação: uma análise crítica. Rev. Saúde Pública, São Paulo, v. 52, p. 40, 2018. Disponível em $<$ http://www.scielo.br/scielo.php?script=sci_arttext\&pid=S00 $34-89102018000100504 \& \operatorname{lng}=\mathrm{en} \& n r m=i s o>$. Acesso em 24 Nov. 2020. DOI: https://doi.org/10.11606/s15188787.2018052000384

ARAGÃO, R.F.; ALBUQUERQUE, I.M.N.; RIBEIRO, M.A.; BARRETO, R.M.; SOUSA, J.A. Percepções e conhecimentos da equipe de enfermagem sobre o processo de imunização. Rev Bras Promoç Saúde, v. 32, n. 8809, p. 1-8, 2019. DOI: https://doi.org/10.5020/18061230.2019.8809

BARBIERI, C. L. A.; COUTO, M. T.; AITH, F. M. A. A (não) vacinação infantil entre a cultura e a lei: os significados atribuídos por casais de camadas médias de São Paulo, Brasil. Cad. Saúde Pública, Rio de Janeiro, v. 33, n. 2, e00173315, 2017. Disponível $\mathrm{em}$ <http://www.scielo.br/scielo.php?script=sci_arttext\&pid=S01 02-311X2017000205004\&lng=en\&nrm=iso $>$. Acesso em 24 Nov. 2020. DOI: https://doi.org/10.1590/0102-311x00173315.

BARBIERI, C. L. A. et al. Cobertura vacinal infantil em um serviço filantrópico de atenção primária à saúde do município de São Paulo, estado de São Paulo, Brasil, em 2010. Epidemiol. Serv. Saúde, Brasília, v. 22, n. 1, p. 129-139, mar.2013. Disponível em <http://scielo.iec.gov.br/scielo.php?script=sci_arttext\&pid=S 1679-49742013000100014\&lng=pt\&nrm=iso $>$. acesso em 23 nov. 2020. DOI: http://dx.doi.org/10.5123/S167949742013000100014.

CAMARGO JR, Kenneth Rochel de. Lá vamos nós outra vez: a reemergência do ativismo antivacina na Internet. Cad. Saúde Pública, Rio de Janeiro, v. 36, supl. 2, e00037620, 2020. Disponível

em <http://www.scielo.br/scielo.php?script=sci_arttext\&pid=S01 02-311X2020001403001\&lng=pt\&nrm=iso $>$. acesso em 24 nov. 2020. DOI: https://doi.org/10.1590/0102311x00037620.CARNEIRO, $\quad S . \quad$ G.; RIBEIRO, T. T.; CARDOSO, M. D. T.; STRAPASSON, J. F.; COSTA, A. F. B.;
GUINA, F. D. Avaliação da Cobertura Vacinal em crianças de 2 meses a 5 anos na Estratégia Saúde da Família. Cadernos UniFOA, 2013, n 22, p. 63-7. DOI: https://doi.org/10.47385/cadunifoa.v8i22.118

CAVALCANTI, M. A. F.; NASCIMENTO, E. G. C. Aspectos intervenientes da criança, da família e dos serviços de saúde na imunização infantil. Rev. Soc. Bras. Enferm. Ped. v.15, n.1, p 31-7, Junho, 2015.

CNN Brasil [Website da Internet]. Estudo aponta queda de vacinação de bebês e crianças nos últimos dois anos. Acesso em 28/09/20. Disponível em: https://www.cnnbrasil.com.br/saude/2020/08/05/estudoaponta-queda-de-vacinacao-de-bebes-e-criancas-nos-ultimosdois-anos.

COSTA, I. Educação para a Saúde como Estratégia de Promoção da Vacinação.2016. Dissertação (Mestrado em Enfermagem Comunitária) - Escola Superior de Saúde. Santarém, 2016.

RODRIGUES, M. V. Qualidade de vida no trabalho. 1989. 180 f. Dissertação (Mestrado em Administração) - Faculdade de Ciências Econômicas, Universidade Federal de Minas Gerais, Belo Horizonte, 1989. DE CASTRO, J. M.;

CABRERA, G. P. B. Avaliação da Cobertura Vacinal em Menores de Cinco em um Município do Leste de Minas Gerais. Ensaios e Ciência: Ciências Biológicas, Agrárias e da Saúde [Internet], v. 21, n. 1, p. 36-41, 2017. Disponível em: https://www.redalyc.org/articulo.oa?id=26051636005 .

ELISIÁRIO, R. N.; SIMAN, A. G.; MOREIRA, T. R.; CARVALHO, C. A.; AMARO, M. de O. F. Avaliação das salas de vacinas nas unidades de estratégia de saúde da família. Rev. Enfermagem, Viçosa, v. 20, n. 3, p. 1-17, 2017. Disponível em http://periodicos.pucminas.br/index.php/enfermagemrevista/a rticle/view/17228. Acesso em 24 Nov 2020.

FERNANDES, A. C. N. et al . Análise da situação vacinal de crianças pré-escolares em Teresina (PI). Rev. bras. epidemiol., São Paulo, v. 18, n. 4, p. 870-882, Dec. 2015. Disponível em <http://www.scielo.br/scielo.php?script=sci_arttext\&pid=S14 $15-790 X 2015000400870 \& \operatorname{lng}=$ en\&nrm=iso $>$. Acesso em 24 Nov. 2020. DOI: https://doi.org/10.1590/1980- 
5497201500040015.

FERREIRA, A. V.; et al. Acesso à sala de vacinas nos serviços de atenção primária à saúde. Revista Eletrônica de Enfermagem, v. 19, 28 nov. 2017. DOI: https://doi.org/10.5216/ree.v19.42468

FILGUEIRAS, R.S.; SCHAUSTZ, M.L.R.; FILGUEIRAS, O.S.; FONSECA, S.C. Cobertura vacinal em crianças de até dois anos: o prontuário eletrônico no município do Rio de Janeiro. Acad. Rev. Cient. da Saúde, Rio de Janeiro. v. 3 n.1, p. 39-45, 2018. Disponível em: https://smsrio.org/revista/index.php/reva/article/view/402. DOI: $10.24118 /$ reva1806.9495.3.12018.402.

Globo-Bem estar. [Website da Internet]. Metade das crianças brasileiras não recebeu todas as vacinas que deveria em 2020, apontam dados do Ministério da Saúde. Disponível em: https://g1.globo.com/bemestar/vacina/noticia/2020/09/08/met ade-das-criancas-brasileiras-nao-receberam-todas-as-vacinasque-deveriam-em-2020-apontam-dados-do-ministerio-dasaude.ghtml . Acesso em: 30 Set. 2020.

IGREJA, P.N.; MOIA, M.Y.S.; REIS, D.L.A.; FERREIRA, A.R.S.; CARDOSO, G.N.G.; OLIVEIRA, R.S. Percepção das mães acerca da vacinação infantil em uma estratégia de saúde da família de Tucuruí-PA. Braz. J. of Develop.,Curitiba, v. 6 , n. 3 , p. 9731-9745, mar. 2020. DOI: https://doi.org/10.34117/bjdv6n3-012

JESUS, A. S. de; et al . Aspectos bioéticos da vacinação em massa no Brasil. Acta bioeth., Santiago, v. 22, n. 2, p. 263 268, nov. 2016. Disponível em $<$ https://scielo.conicyt.cl/scielo.php?script=sci_arttext\&pid=S 1726-569X2016000200013\&lng=es\&nrm=iso>. Acesso em 23 nov. 2020. DOI: http://dx.doi.org/10.4067/S1726569X2016000200013.

NASCIMENTO, LC.; CAVALCANTI, A.C.; SILVA, M.M.M. Atuação da enfermagem na compreensão dos genitores acerca da importância da imunização infantil: Revisão integrativa. Rev. Bra. Edu. Saúde, v. 10, n.3, p. 115120, 2020. DOI: https://doi.org/10.18378/rebes.v10i3.7891

OLIVEIRA, G.S.; BITENCOURT, E.L.; AMARAL, P.F.F.; VAZ, G.P.; REIS JÚNIOR, P.M. Cobertura vacinal: uma análise comparativa entre os estados da região norte do Brasil. Revista de Patologia do Tocantins, v. 7, n. 1, p. 14-17, 2020. DOI: $10.20873 /$ uft.2446-6492.2020v7n1p

OLIVEIRA, M. F. S. de; MARTINEZ, E. Z.; ROCHA, J. S. Y. Fatores associados à cobertura vacinal em menores de cinco anos em Angola. Rev. Saúde Pública, São Paulo, v. 48, n. 6 , p. 906-915, Dec. 2014. Disponível em $<$ http://www.scielo.br/scielo.php?script=sci_arttext\&pid=S00 34-89102014000600906\&lng=en\&nrm=iso>. Acesso em 24
Nov. 2020. DOI: https://doi.org/10.1590/s00348910.2014048005284 .

PEIXOTO, M.C.; TORRES, M.T.; PASSOS, N.C.R.; ALMEIDA, T.S.C. Perfil vacinal da população infantil em um município do recôncavo baiano. Textura, v. 10, n. 19, p. 172179, Dez. 2017. Disponível em https://textura.famam.com.br/textura/article/view/55. Acesso em 24 Nov. 2020.

PEREIRA, Alcione Matos; IVO, Olguimar Pereira. Causas do atraso do calendário vacinal em menores de dois anos. Revista Enfermagem Contemporânea, [S.1.], v. 5, n. 2, nov. 2016. ISSN 2317-3378. Disponível em: $<$ https://www5.bahiana.edu.br/index.php/enfermagem/article/ view/1068>. Acesso em: 24 nov. 2020. DOI: http://dx.doi.org/10.17267/2317-3378rec.v5i2.1068.

PEREIRA, D. D. dos S. et al . Análise da taxa de utilização e perda de vacinas no programa nacional de imunização. Cad. saúde colet., Rio de Janeiro, v. 21, n. 4, p. 420-424, 2013. Disponível em <http://www.scielo.br/scielo.php?script=sci_arttext\&pid=S14 14-462X2013000400010\&lng=en\&nrm=iso>. Acesso em 24 Nov. 2020. DOI: https://doi.org/10.1590/S1414462X2013000400010.

ROCHA, G. Programa nacional de imunização (PNI). Blog da Saúde [periódico online]. Acesso em: 29/09/20. Disponível em: http://www.blog.saude.gov.br/index.php/entenda-osus/50027-programanacional-de-imunizacoes-pni.

SANCHES, S. H. Dal F. N.; CAVALCANTI, A. E. L. W. Direito à Saúde na Sociedade da Informação: A Questão das Fake News e seus Impactos na Vacinação. Revista Juridica, [S.1.], v. 3, n. 52, p. 448 - 466, set. 2018. ISSN 2316-753X. Disponível em: <http://revista.unicuritiba.edu.br/index.php/RevJur/article/vie w/3227>. Acesso em: 24 nov. 2020. DOI: http://dx.doi.org/10.21902/revistajur.2316-753X.v53i4.3227.

SANTOS, M.Q.S; ARAÚJO, L.E.; SOUSA, C.C.F.; ARAÚJO, G.F.; REZENDE, G.M.S. O conhecimento sobre o calendário vacinal infantil até 15 meses de idade entre seus acompanhantes e os profissionais de saúde. Braz. J. of Develop., Curitiba, v. 6, n.4, p.18262-18276, 2020. DOI: 10.34117/bjdv6n4-119

SILVA, I.C.; CUNHA, C. A importância do enfermeiro na sala de vacina em uma unidade básica de saúde. Empatia - revista de saúde integral, v.1, n 1, p. 157-169, 2018.

SINDSAÚDE. [Website da Internet]. Brasil não atingiu a meta para nenhuma das principais vacinas indicadas a crianças de até um ano. Acesso em 30/09/20. Disponível em: https://sindsaude.org.br/noticias/na-midia/brasil-nao-atingiu- 
a-meta-para-nenhuma-das-principais-vacinas-indicadas-acriancas-de-ate-um-ano .

SOARES, J. S.; SILVA, E. S. F. da; SOUSA, W. R. M.; ARAÚJO, L. R. de S.; BARBOSA, T. DE J. A.; et al. Conhecimento das mães sobre as vacinas administradas aos menores de um ano. Revista Eletrônica Acervo Saúde, n. 43, p. e1000, 27 ago. 2020.

SOUSA, C. de J.; VIGO, Z. de L.; PALMEIRA, C. S. Compreensão dos pais acerca da importância da vacinação infantil. Revista Enfermagem Contemporânea, [S.1.], v. 1, n. 1, dez. 2012. ISSN 2317-3378. Disponível em: <https://www5.bahiana.edu.br/index.php/enfermagem/article/ view/39>. Acesso em: 23 nov. 2020. DOI: http://dx.doi.org/10.17267/2317-3378rec.v1i1.39.

STÁBILI, A.P.; BRAZ, J.C.; FURTADO, M.C.C.; MELLO, D.F. Indicadores de saúde infantil na estratégia saúde da família no Brasil: revisão integrativa da literatura. Rev. Ciênc. Méd., Campinas, v. 22, n. 1, p. 31-41, 2013. DOI: https://doi.org/10.24220/2318-0897v22n1a1999 